\title{
ADAPTIVE SEASONAL VARIATION IN GRASSHOPPER OFFSPRING SIZE
}

\author{
KeITH LANDA ${ }^{1}$ \\ Department of Biology, University of Michigan, Ann Arbor, MI 48109 USA
}

\begin{abstract}
Key words. - Acrididae, grasshoppers, life history, offspring fitness, optimal offspring size, phenotypic plasticity, seasonality.
\end{abstract}

\section{Received July 22, 1991. Accepted March 23, 1992.}

Offspring size has been reported to vary seasonally in a diverse group of organisms: for example, flowering plants, isopods, cladocerans, insects, fish, amphibians, and reptiles (Wellington, 1965; Leonard, 1970; Kerfoot, 1974; Harvey, 1977; Ware, 1977; Howard, 1978; Richards and Myers, 1980; Nussbaum, 1981; Ferguson et al., 1982; Brody and Lawlor, 1984; Cavers and Steel, 1984; Marsh, 1984; Wiklund and Karlsson, 1984; Perrin, 1988; DeMarco, 1989; McGinley, 1989; Dangerfield and Telford, 1990). Seasonal increases and decreases in offspring size are both common, and some populations show even more complex responses. These studies have shown population level changes in offspring size, as well as phenotypic plasticity by individual females, with varying offspring sizes produced among a female's successive clutches. Although there has been some discussion relating observed seasonal changes in offspring size with seasonal changes in biotic and abiotic conditions (e.g., Kerfoot, 1974; Brody and Lawlor, 1984; Perrin, 1988), more work is needed concerning whether these seasonal responses are adaptive or not and, if adaptive, what selective pressures favor such plasticity.

Many theoretical models have been developed, beginning with Smith and Fretwell (1974), which predict optimal offspring size, based on the relationship between offspring size and offspring fitness (e.g., Smith and Fretwell, 1974; Brockelman, 1975; Pianka, 1976; Parker and Begon, 1986; Winkler and Wallin, 1987; McGinley et al., 1987). Investing fewer resources per offspring is assumed to allow parents to produce more offspring, increasing a parent's potential fecundity. However, fewer resources per offspring may decrease offspring fitness, with the result that each individual offspring contributes less to parental fitness. The optimal offspring size maximizes parental fitness: the product of offspring number and offspring fitness. One general prediction of these models is that offspring size should increase under conditions that decrease offspring survival and/or future reproduction (Sibly and Calow, 1983; Taylor and Williams, 1984; McGinley et al., 1987).

These models have been explicitly applied to seasonal changes in offspring size (McGinley et al., 1987). Offspring fitness may change seasonally due to changing abiotic and biotic conditions (Dixon, 1976; Lacey, 1982; Ohgushi, 1986; Kalisz, 1986). Consistent withinyear variation in environmental conditions affecting

${ }^{1}$ Present address: Department of Biology, Indiana University, Bloomington, IN 47405 USA. offspring survival or reproduction can select for seasonal changes in optimal offspring size, with offspring hatching out into poorer conditions expected to be larger (McGinley et al., 1987). For such adaptive seasonal changes in offspring size to be selected, however, females must be capable of forcasting future environmental conditions; the time when resources are being allocated among offspring must be predictive of the conditions that offspring will experience. Any physiological processes or environmental factors that uncouple hatching time from the time that females provision offspring would weaken the evolution of adaptive seasonal changes in offspring size, in response to seasonal changes in offspring fitness.

Variation in life cycles among temperate grasshoppers provides a suitable system for testing whether predictable seasonal changes in offspring fitness can select for the evolution of adaptive seasonal changes in offspring size. Some grasshopper species overwinter as late instar nymphs. These grasshoppers hatch during the summer from eggs laid earlier in the same growing season. Nymphs pass through several instars by the end of fall, overwinter frozen at the soil surface, and molt to adults the following spring. Previous work (Landa, 1992) on Arphia sulphurea (Fabricus) and Chortophaga viridifasciata (DeGeer), two nymphoverwintering species, suggests that they meet both criteria for the evolution of adaptive seasonal changes in offspring size. 1) There are consistent seasonal declines in offspring fitness, in that late-hatching nymphs grow to a smaller size before winter and experience greater size-dependent overwinter mortality than early-hatching nymphs. 2) Hatching date is highly correlated with oviposition date ( $\mathrm{R}^{2}=99 \%$ for both species), indicating a lack of embryonic diapause. The time that eggs are being provisioned is therefore predictive of the time at which nymphs will hatch and the conditions that they will experience. If seasonal declines in offspring fitness have been important selective pressures in the evolution of offspring size in $A$. sulphurea and $C$. viridifasciata, then I predict that these two species will increase offspring size over the course of their breeding seasons. $C$. viridifasciata experiences steeper seasonal declines in offspring fitness than $A$. sulphurea (Landa, 1992), and should therefore display more pronounced seasonal changes in offspring size.

The seasonal increases in offspring size predicted for A. sulphurea and $C$. viridifasciata can arise from two complementary mechanisms. Female grasshoppers oviposit repeatedly during their adult life span, with intervals of days or more separating successive egg pods. During interpod intervals females feed and yolk up the 
next clutch of eggs. Selection for seasonal increases in offspring size may result in phenotypic plasticity within individual females, with females producing larger offspring in their later clutches. In addition, where there is intra-population variation in the timing of adult maturation, later-molting females could produce, on average, larger offspring. Both within-female and between-female seasonal changes in offspring size will be examined in this paper.

The optimal offspring size models which predict seasonal increases in offspring size for $A$. sulphurea and $C$. viridifasciata assume that offspring fitness increases with offspring size, at least over some range of offspring sizes. A complementary approach to evaluating the utility of these models in understanding the evolution of seasonal changes in offspring size is therefore to check whether this assumption is met by $A$. sulphurea and $C$. viridifasciata. The primary determinant of offspring survival in $A$. sulphurea and $C$. viridifasciata is the body size attained before winter, and the corresponding level of size-dependent overwinter mortality (Landa, 1992). Prewinter body size, in turn, is largely a function of hatching date. To test the assumption that offspring fitness is correlated with size, therefore, I examine whether or not offspring size has additional effects on prewinter body size, beyond hatching date effects. That is, do larger offspring grow to a larger size before winter than smaller offspring that hatch on the same date?

In contrast to the offspring size data for $A$. sulphurea and $C$. viridifasciata, I also present data on egg size variation for Dissosteira carolina (L.). As is the case for most temperate grasshoppers, $D$. carolina overwinters as eggs (Otte, 1981, 1984). Nymphs of egg-overwintering species hatch in the spring, molt to adults by summer, and lay eggs during the summer and fall. Eggs overwinter either in diapause or with embryonic development arrested by low temperatures (Uvarov, 1966). Compared to nymph-overwintering species, there is little correlation between oviposition date in one year and hatching date the following spring for eggoverwintering grasshoppers (Parker, 1930; Richards and Waloof, 1954; Pickford, 1966), due to the combination of embryonic diapause and environmental variability during the embryonic period. This uncoupling would tend to weaken the evolution of adaptive seasonal changes in offspring size for egg-overwintering grasshoppers. However, offspring fitness may still vary with oviposition date; for example, embryonic mortality may vary with the length of time eggs remain in diapause. I have not examined the effect of oviposition date on offspring fitness in $D$. carolina, and therefore cannot rule out adaptive seasonal changes in offspring size, a priori. I compare seasonal variation in offspring size for this species to that for $A$. sulphurea and $C$. viridifasciata because $D$. carolina is in the same subfamily as $A$. sulphurea and $C$. viridifasciata, it has a contrasting life cycle to the nymph-overwintering species and I had previously collected egg size data on $D$. carolina as part of a different study on the cost of reproduction in this species.

\section{Materials AND Methods}

In order to measure seasonal changes in offspring size for known females, immature grasshoppers were collected from natural populations and maintained in individual field cages at the Matthaei Botanical Gardens of the University of Michigan (Landa, 1989). Nymphs of $D$. carolina were collected from an old-field habitat adjacent to Horner Woods on the north side of Ann Arbor, Michigan, at the beginning of July 1983, while $A$. sulphurea and $C$. viridifasciata nymphs were collected during mid May 1984, from the E. S. George Reserve, an enclosed natural area in southeastern Michigan. As females of each species matured, they were mated and set up in individual oviposition cages, which contained moist sand in the bottom for depositing egg pods. Grasshoppers were fed an excess of fresh grass ( $P O a$ and Bromus) harvested from old-fields at Matthaei and kept hydrated in bottles of water within the cages. All cages were exposed to ambient temperature, isolation, and photoperiod, which allowed opportunities for the grasshoppers to thermoregulate behaviorally.

Oviposition cages were checked for egg pods approximately every three days, by sifting the sand substrate of the cage through a screen mesh. The midpoint of the interval between checks was taken as the oviposition date for any egg pods found (usually one or none). Offspring size for $A$. sulphurea and $C$. viridifasciata was determined by hatching out nymphs from each egg pod under natural conditions (Landa, 1989) and measuring the dry weight of a random subsample of 5 to 10 hatchlings from each egg pod, depending on the total number of hatchlings from each pod. $D$. carolina offspring size was determined by dissecting each egg pod and measuring the dry weight of a random subsample of 10 eggs per pod. I took egg size data for $D$. carolina because these results were originally part of a different study on reproductive effort in this species. I assume that offspring size is correlated with egg size in $D$. carolina and that there are no unusual seasonal trends in the proportion of egg weight that is comprised of chorion and other egg membrane structures.

Within-female seasonal changes in offspring size were characterized by regressing offspring size against oviposition date separately for each female for which I had data on three or more pods. Some $A$. sulphurea and $C$. viridifasciata egg pods were lost to fungal infection during incubation and a few females produced only one or two egg pods. The slopes of these regressions were used as indices of whether individual females increased or decreased offspring size among successive egg pods. Because the regression slope distributions for $C$. viridifasciata and $D$. carolina were marginally non-normal (Fig. 2), I used non-parametric tests to evaluate differences in the distributions (SAS, 1985). I used signed rank scores (SAS PROC UNIVARIATE) to test whether the average within-female seasonal response for each species was significantly different from zero, and the Kruskal-Wallis test (SAS PROC NPAR I WAY) to test the significance of species differences. Similar results were obtained using $t$-tests and ANOVA.

Between-female differences in offspring size that relate to seasonal changes were assessed by first calculating the mean offspring size for each female. Multiple linear regression was then used to relate female mean offspring sizes with both timing of maturation (as measured by date of first oviposition) and female body size. Pronotum length, which correlates well with adult body 
size (Dean, 1982), was measured at the time of death and used as an index of female size. Pronotum size is fixed when the adult exoskeleton hardens and does not change in size thereafter. In total, $44 \mathrm{~A}$. sulphurea females, $28 C$. viridifasciata females, and $19 \mathrm{D}$. carolina females were examined for offspring size variation.

To confirm that $A$. sulphurea and $C$. viridifasciata meet the assumption that offspring fitness increases with offspring size, I maintained nymphs of $A$. sulphurea and $C$. viridifasciata not used for hatchling dry weight analysis in field cages throughout the fall and winter (Landa, 1989). Experimental manipulation of hatching time was used to separate the effects of hatching time from seasonal changes in offspring size (Landa, 1992). I measured mean wet weight at the beginning of November for the cohort of nymphs from each egg pod, to assess prewinter body size. To determine whether hatchling size had any effect on prewinter size in addition to the major effects already observed for hatching date (Landa, 1992), I used type I sums of squares in a regression analysis, including hatching date effects in the model first and asking whether hatchling size explained any of the residual variance in prewinter body size (SAS, 1985). The added effect of offspring size was visualized by calculating residuals from the relationship between prewinter size and hatching date and plotting the residuals against hatchling dry weight.

\section{RESULTS}

Larger hatchlings of both nymph-overwintering species grew to larger sizes before winter than small offspring, once effects of hatching date are factored out (Fig. 1). Hatchling size explained $16 \%$ of the residual variance in $C$. viridifasciata prewinter body size $\left(F_{1,47}\right.$ $=11.33, P=0.0015)$. The effect in $A$. sulphurea, although still significant, is much smaller, with only $4 \%$ of the residual variance in prewinter weight explained by hatchling size $\left(F_{1,101}=4.35, P=0.039\right)$. $C$. viridifasciata, therefore, better fits the assumptions of optimal offspring size models than does $A$. sulphurea.

Females of the three species displayed a progression of seasonal changes in offspring size among successive clutches (Fig. 2). Out of $24 \mathrm{C}$. viridifasciata females, 22 increased offspring size in their later clutches, with an average response across females of $+8.13 \pm 7.45$ $\mu \mathrm{g} /$ day (signed rank test, $P=0.0001$ ). A. sulphurea females also tended to increase offspring size in later clutches, although the response was not significantly different from zero (signed rank test, $P=0.11$ ). Average A. sulphurea response was $+2.99 \pm 10.56 \mu \mathrm{g} / \mathrm{day}$, with 17 out of 27 females having positive slopes. Alternatively, $D$. carolina females decreased offspring size over successive clutches (signed rank test, $P=0.018$ ). Average $D$. carolina response was $-5.74 \pm 9.86 \mu \mathrm{g} /$ day, with 15 out of 19 females decreasing offspring size. These species differences in within-female seasonal changes in offspring size were highly significant (Kruskal-Wallis test, $P=0.0001$ ).

All three species showed similar trends for the effects of body size and timing of maturation on mean offspring size (Table 1). Mean offspring size increased among females that began reproducing later, and larger females produced larger offspring. Female body size and onset of reproduction were themselves uncorrelated in all of the species, however $(P=0.3,0.8$, and 0.9 for $C$. viridifasciata, $A$. sulphurea, and $D$. carolina,

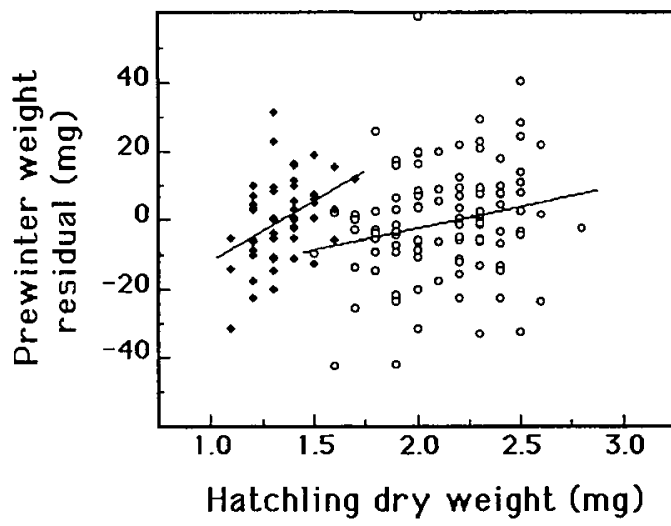

FIG. 1. Effect of hatchling size on prewinter body size in $A$. sulphurea and $C$. viridifasciata. Offspring fitness in these species is primarily a function of hatching date (Landa, 1992), in that late hatching nymphs grow to a smaller size before winter and experience higher size-dependent mortality during the winter. Residuals from regressions of prewinter size against hatching date are plotted against hatchling size, to show whether or not offspring size affects prewinter body size, once hatching date effects are factored out. Data for $A$. sulphurea are given by the open circles; data for $C$. viridifasciata are the closed diamonds. The lines represent least squares fits to the two data sets.

respectively). There was also a negative interaction between between body size and maturation timing on mean offspring size, indicating that small females showed greater increases in mean offspring size as a function of maturation timing than did big females.

The three species varied in the significance of between-female effects, however. All of the between-female effects on mean offspring size were significant for C. viridifasciata. The pattern was somewhat less striking for $A$. sulphurea, with the body size effect and the interaction term significant and the timing effect marginally significant. None of the between-female effects for $D$. carolina were significant. This may be a result of low statistical power, however, given the smaller number of $D$. carolina females analyzed. Dropping the interaction term yields a reduced model in which both timing and body size effects are significant, and in the same direction as for the other two species (Table 1).

\section{Discussion}

The seasonal variation in offspring size displayed by these three grasshoppers support the predictions of optimal offspring size models, based on seasonal changes in offspring fitness and the ability of females to forecast conditions at the time when eggs are being provisioned. C. viridifasciata females were predicted to show strong seasonal increases in offspring size, as a result of steep seasonal declines in offspring fitness (Landa, 1992). In addition, current results indicate that $C$. viridifasciata meets the assumption that offspring fitness increases with offspring size. $C$. viridifasciata females were highly uniform in their within-female increases and also showed seasonal increases between females in response to differences in maturation time. As a result, there was 


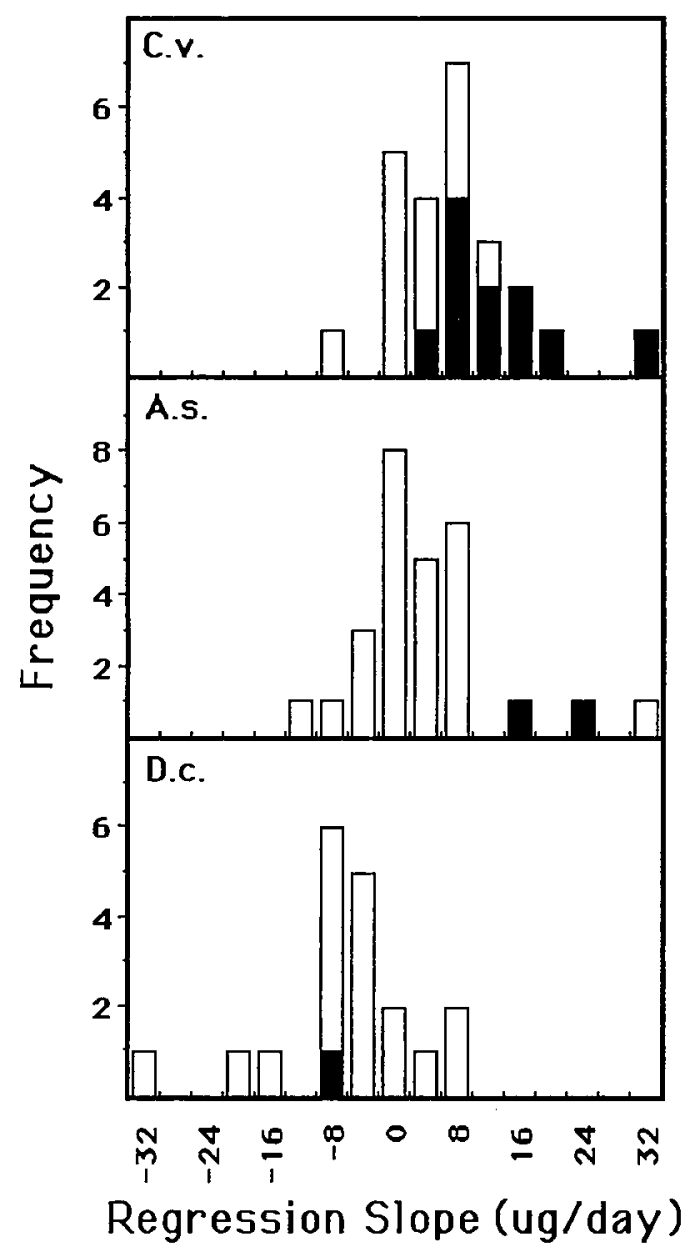

FIG. 2. Frequency distributions for within-female seasonal changes in offspring sizes, by species. Regressions of offspring size against oviposition date were done separately for each female and the slopes ( $\mu \mathrm{g} / \mathrm{day})$ were grouped into intervals of $4 \mu \mathrm{g} /$ day. Numbers on the abscissa represent interval midpoints. Solid bars are slopes from significant regressions; open bars are from non-significant regressions and are stacked on top of the solid bars. Abbrev: A.s. = A. sulphurea, C.v. = C. viridifasciata, D.c. $=D$. carolina.

an overall, population-level increase in offspring size over the breeding season. This pattern is consistent with the hypothesis that all females in the $C$. viridifasciata population track an optimal offspring size which increases regularly throughout the breeding season. $A$. sulphurea females were expected to show weaker increases in offspring size, as offspring fitness does not decline as rapidly with hatching date (Landa, 1992). Current results also show that $A$. sulphurea offspring fitness is less affected by offspring size, compared to $C$. viridifasciata. Correspondingly, $A$. sulphurea females exhibited similar within- and between-female seasonal patterns as $C$. viridifasciata females, but their responses were more variable and less significant. This variability
TABLE 1. Multiple linear regressions of mean offspring size for each female against female body size and maturation time. Pronotum length ( $\mathrm{mm}$ ) was used as the measure of body size and date of first oviposition was used as maturation time. Error degrees of freedom (edf) are 23 for $C$. viridifasciata; 40 for $A$. sulphurea; 15 for $D$. carolina, full model; and 16 for $D$. carolina, reduced model.

\begin{tabular}{lrrc}
\hline \hline & Estimate (std err) & $F_{1, \text { cdf }}$ & $P$ \\
\hline $\begin{array}{l}\text { C. viridifasciata } \\
\text { Maturation time }\end{array}$ & & & \\
Female body & & & \\
$\quad$ size & $1.617(0.630)$ & 6.60 & 0.017 \\
MT $\times$ FBS & $-0.009(0.004)$ & 5.20 & 0.032
\end{tabular}

A. sulphurea

Maturation time $\quad 0.091(0.045) \quad 4.04 \quad 0.051$

Female body

size

MT $\times$ FBS

$2.433(1.130) \quad 4.62 \quad 0.037$

$\begin{array}{lll}-0.015(0.007) & 4.45 & 0.041\end{array}$

D. carolina, full model

$\begin{array}{lrrr}\text { Maturation time } & 0.014(0.019) & 0.59 & 0.45 \\ \text { Female body } & & & \\ \quad \text { size } & 0.242(0.673) & 0.13 & 0.72 \\ \text { MT } \times \text { FBS } & -0.001(0.003) & 0.08 & 0.78\end{array}$

$D$. carolina, reduced model

\begin{tabular}{llll}
$\begin{array}{l}\text { Maturation time } \\
\text { Female body } \\
\text { size }\end{array}$ & $0.009(0.004)$ & 6.30 & 0.023 \\
& $0.054(0.026)$ & 4.58 & 0.049 \\
\hline
\end{tabular}

resulted in a lack of population-level correlation between oviposition date and offspring size for $A$. sulphurea.

In contrast to $C$. viridifasciata and $A$. sulphurea, $D$. carolina females actually decreased offspring size over successive clutches. This is a common pattern in insects, and is often attributed to the effects of senescence (but see, Begon and Parker, 1986). Although no a priori predictions were possible concerning seasonal changes in offspring size for $D$. carolina, the within-female seasonal declines in offspring size for this species stands in marked contrast to the within-female seasonal increases seen in the nymph-overwintering species, $C$. viridifasciata and $A$. sulphurea.

As an alternative to optimal offspring models based on selection due to variation in offspring fitness, Nussbaum (1981) proposed a combination of bet-hedging and fractional egg models to explain population-level seasonal increases in lizard egg size. Under this scenario, females are selected to produce smaller clutches late in the breeding season, due to uncertainty about the ability to provision a large clutch before the end of the breeding season. Any excess resources obtained would be divided among fewer offspring late in the breeding season, therefore, resulting in seasonal increases in offspring size. This model applies to organisms that provision clutches of offspring simultaneously, as is the case for grasshoppers. This model is falsified if the resources used to increase offspring size in late season clutches are sufficient to produce an additional 
offspring equivalent to the early season size (Nussbaum, 1981).

C. viridifasciata displayed population-level seasonal increases in offspring size, corresponding to that modeled by Nussbaum (1981). As would be expected from the bet-hedging/fractional egg model, average clutch sizes for $C$. viridifasciata females declined during the breeding season (Landa, 1992), from approximately 19 at the beginning of June to about 11 in mid July. Over this same period, however, offspring size increased from $1.22 \mathrm{mg}$ to $1.47 \mathrm{mg}$. In the absence of seasonal increases in offspring size, $C$. viridifasciata females could have produced an additional 2.2 nymphs per late season pod. The increases in $C$. viridifasciata offspring size, therefore, are larger then predicted by a simple interpretation of the bet-hedging/fractional egg model.

Between-female differences in mean offspring size were positively correlated with both female body size and timing of maturation. Positive phenotypic correlations between maternal size and offspring size have been seen in numerous organisms and have recently been included into optimal offspring size theory (e.g., Parker and Begon, 1986; Winkler and Wallin, 1987). Less well documented, however, is the type of negative interaction seen in this study between maternal size and seasonal increases in offspring size between females. This negative interaction may indicate that the larger offspring sizes of large females are closer to some species-specific upper limit on offspring size and therefore large females have less leeway to increase offspring size seasonally.

In conclusion, the seasonal variation in offspring size seen in $C$. viridifasciata and $A$. sulphurea can best be explained as adaptive responses to the selection resulting from seasonal declines in offspring fitness. This is especially true for $C$. viridifasciata, which not only shows stronger seasonal declines in offspring fitness (Landa, 1992) but also better meets the assumption that offspring size is positively correlated with offspring fitness.

\section{ACKNOWLEDGMENTS}

I thank L. Landa, for assistance in the field and lab; the staff of the Matthaei Botanical Gardens, for use of their facilities; and B. Rathcke and D. Schultz, for discussions concerning this research. D. Reznick and three anonymous reviewers provided helpful comments on earlier versions of this paper. This work was supported by graduate research funds from the Rackham Graduate School, University of Michigan.

\section{Literature Cited}

Begon, M., AND G. A. Parker. 1986. Should egg size and clutch size decrease with age? Oikos 47:293302.

Brockelman, W. Y. 1975. Competition, the fitness of offspring, and optimal clutch size. Am. Nat. 109: 677-699.

Brody, M. S., AND L. R. LAwLoR. 1984. Adaptive variation in offspring size in the terrestrial isopod, Armadillidium vulgare. Oecologia 61:55-59.

Cavers, P. B., ANd M. G. Steel. 1984. Patterns of change in seed weight over time on individual plants. Am. Nat. 124:324-335.

Dangerfield, J. M., AND S. R. Telford. 1990.
Breeding phenology, variation in reproductive effort and offspring size in a tropical population of the woodlouse, Porcellionides pruinosus. Oecologia $82: 251-258$.

DEAN, J. M. 1982. Control of diapause induction by a change in photoperiod in Melanoplus sanguinipes. J. Insect Physiol. 28:1035-1040.

DeMarco, V. G. 1989. Annual variation in the seasonal shift in egg size and clutch size in Sceloperus woodi. Oecologia 80:525-532.

Dixon, A. F. G. 1976. Timing of egg hatch and viability of the sycamore aphid Drepanosiphum platanoides (Schr.), at bud burst of sycamore, Acer psuedoplatanus L. J. Anim. Ecol. 45:593-603.

Ferguson, G. W., K. L. Brown, and V. G. DeMarco. 1982. Selective basis for the evolution of variable egg and hatchling size in some iguanid lizards. Herpetologica 38:178-188.

HaRvey, G. T. 1977. Mean weight and rearing performance of successive egg clusters of eastern spruce budworm (Lepidoptera: Tortricidae). Can. Entomol. 109:487-496.

Howard, R. D. 1978. The influence of male-defended oviposition sites on early embryo mortality in bullfrogs. Ecology 59:789-798.

KaLISZ, S. 1986. Variable selection on the timing of germination in Collinsia verna (Scrophulariaceae). Evolution 40:479-491.

KERFOOT, W. C. 1974. Egg size cycle of a cladoceran. Ecology 55:1259-1270.

LACEY, E. P. 1982. Timing of seed dispersal in Daucus carota. Oikos 39:83-91.

LANDA, K. 1989. Seasonal variation of life history traits in the nymph-overwintering grasshoppers, Arphia sulphurea and Chortophaga viridifasciata. Ph.D. Thesis. University of Michigan, Ann Arbor, MI USA.

- 1992. Seasonal declines in offspring fitness and selection for early reproduction in nymphoverwintering grasshoppers. Evolution, 46:121-135.

LEONARD, D. E. 1970. Intrinsic factors causing qualitative changes in populations of Porthetria dispar (Lepidoptera: Lymantriidae). Can. Entomol. 102: 239-249.

MARSH, E. 1984. Egg size variation in central Texas population of Etheostoma spectabile (Pisces: Perchidae). Copeia 1984:291-301.

MCGinley, M. A. 1989. Within and among plant variation in seed mass and pappus size in Tragopogon dubious. Can. J. Bot. 67:1298-1304.

McGinley, M. A., D. H. Temme, AND M. A. Geber. 1987. Parental investment in offspring in variable environments: Theoretical and empirical considerations. Am. Nat. 130:370-398.

Nussbaum, R. A. 1981. Seasonal shifts in clutch size and egg size in the side-blotched lizard, Uta stansburiana Baird and Girard. Oecologia 49:8-13.

Ohgushi, T. 1986. Population dynamics of an herbivorous lady beetle, Henosepilachna niponica, in a seasonal environment. J. Anim. Ecol. 55:861879.

Otte, D. 1981. The North American Grasshoppers. Vol 1: Gomphocerinae and Acridinae. Harvard University Press, Cambridge, MA USA.

. 1984. The North American Grasshoppers. 
Vol. 2: Oedipodineae. Harvard University Press, Cambridge, MA USA.

Parker, G. A., AND M. Begon. 1986. Optimal egg size and clutch size: Effects of environment and maternal phenotype. Am. Nat. 128:573-592.

PARKer, J. R, 1930. Some effects of temperature and moisture upon Melanoplus mexicanus mexicanus Saussure and Camnula pellucida Scudder (Orthoptera). Mont. Agric. Exp. Stn. Bull. 233:1-132.

Perrin, N. 1988. Why are offspring born larger when it is colder? Phenotypic plasticity for offspring size in the cladoceran Simocephalus vetulus (Müller). Funct. Ecol. 2:283-288.

PiankA, E. R. 1976. Natural selection of optimal reproductive tactics. Am. Zool. 16:775-784.

PICKFORD, R. 1966. Influence of date of oviposition and climatic conditions on the hatching of Camnula pellucida (Scudder) (Orthoptera: Acrididae). Can. Entomol. 98:1145-1159.

RichaRDS, L. J., AND J. H. MYeRs. 1980. Maternal influences on size and emergence time of the cinnabar moth. Can. J. Zool. 58:1452-1457.

Richards, O. W., AND N. WalofF. 1954. Studies on the biology and population dynamics of British grasshoppers. Anti-Locust Bull. 17:1-182.

SAS. 1985. SAS User's Guide: Statistics. SAS Institute, Inc., Cary, NC USA.

Sibly, R. M., AND P. Calow. 1983. An integrated approach to life-cycle evolution using selective landscapes. J. Theor. Biol. 102:527-547.
Smith, C. C., ANd S. D. Fretwell. 1974. The optimal balance between size and number of offspring. Am. Nat. 108:499-506.

TAYloR, P. D., AND G. C. Williams. 1984. Demographic parameters in evolutionary equilibrium. Can. J. Zool. 62:2264-2271.

Uvarov, B. P. 1966. Grasshoppers and Locusts. A Handbook of General Acridology. Vol. 1: Anatomy, Physiology, Development, Phase Polymophism and Introduction to Taxonomy. Cambridge University Press, London, UK.

WARE, D. M. 1977. Spawning time and egg size of Atlantic mackeral, Scomber scombrus, in relation to plankton. J. Fish. Res. Board Can. 34:2308-2315.

WELLINGTON, W. G. 1965. Some maternal influences on progeny quality in the western tent caterpillar, Malacosoma pluviale (Dyar). Can. Entomol. 97:114.

WIKLUND, C., AND B. KARLSSON. 1984. Egg size variation in satyrid butterflies: Adaptive vs historical, "bauplan" and mechanistic explanations. Oikos 43: $391-400$.

Winkler, D. W., AND K. WALLIN. 1987. Offspring size and number: A life history model linking effort per offspring and total effort. Am. Nat. 129:708720.

Corresponding Editor: D. Reznick

\section{TEMPORAL STABILITY OF THIRD-CHROMOSOME INVERSION FREQUENCIES IN DROSOPHILA PERSIMILIS AND D. PSEUDOOBSCURA}

JERRY A. COYNE,

Department of Ecology and Evolution, The University of Chicago, 1101 E. 57th Street, Chicago, IL 60637 USA

BetTy C. Moore, John A. Moore, Department of Biology, University of California, Riverside, CA 92521 USA

JEFFREY R. POWELL, Department of Biology, Yale University, New Haven, Connecticut 06511 USA

AND

Charles E. TAylor

Department of Biology, University of California, Los Angeles, California 90024 USA

Key words. - Chromosomes, Drosophila persimilis, Drosophila pseudoobscura, inversions.

Received October 31, 1991. Accepted February 21, 1992.

One of the most extensive bodies of data on genetic polymorphism in any species is that on the frequencies of third-chromosome inversions in Drosophila pseudoobscura. For 50 years, beginning with the report of Dobzhansky and Epling (1944) and continuing through the Genetics of Natural Populations series (see Le- wontin et al., 1981; Anderson et al., 1991), Dobzhansky and his colleagues surveyed gene-arrangement frequencies throughout the range of this species. Many locations in western North America were sampled every decade, and some much more frequently.

The polymorphism in $D$. pseudoobscura is complex. 